\title{
Solvent-Annealing-Induced Self-Organization of Poly(3-hexylthiophene), a High-Performance Electrochromic Material
}

\author{
Jen-Hsien Huang, ${ }^{\dagger}$ Chuan-Yi Yang, ${ }^{\mp}$ Chih-Yu Hsu, ${ }^{\dagger}$ Cheng-Lun Chen, ${ }^{\dagger}$ Lu-Yin Lin, ${ }^{\dagger}$ Rui-Ren Wang, ${ }^{\S}$ \\ Kuo-Chuan Ho, ${ }^{*} \dagger, \perp$ and Chih-Wei Chu*, ${ }^{*},, \#$
}

Department of Chemical Engineering, National Taiwan University, Taipei, Taiwan 10617, Institute of Electronic Engineering, National Tsing Hua University, Hsinchu, Taiwan 30013, Department of Product Development, Taiwan Textile Research Institute, Tucheng, Taiwan 23674, Institute of Polymer Science and Engineering, National Taiwan University, Taipei, Taiwan 10617, Department of Photonics, National Chiao-Tung University, Hsinchu, Taiwan 30010, and Research Center for Applied Sciences, Academia Sinica, Taipei, Taiwan 11529

\begin{abstract}
We have systematically studied the self-organization of poly(3-hexylthiophene) (P3HT), an electrochromic material, upon control of the solvent evaporation rate. We characterized these polymer films using atomic force microscopy and X-ray diffraction measurements. Well-ordered P3HT structures were developed after solvent annealing; these highly crystalline structures exhibited enhanced electrochromic contrast and reduced resistance within the film, leading to larger coloration efficiencies and faster switching times. The optical contrast $(\Delta \% T)$, coloration efficiency, and switching time of the P3HT films increased from $54.2 \%, 182.6 \mathrm{~cm}^{2} \mathrm{C}^{-1}$, and $5.3 \mathrm{~s}$, respectively, prior to solvent annealing to $64.8 \%, 293.5 \mathrm{~cm}^{2} \mathrm{C}^{-1}$, and $3.2 \mathrm{~s}$, respectively, after application of the solventannealing conditions.
\end{abstract}

KEYWORDS: electrochromic • electrochemistry • conjugated polymer • poly(3-hexylthiophene) • solvent annealing • self-organization

\section{INTRODUCTION}

lectrochromism can be broadly defined as a reversible color change in response to an externally applied 1 potential. There is worldwide interest in developing electrochromic devices (ECDs) because of their potential applications in light-modulating devices, such as smart windows, antidazzling mirrors, and displays (1-6). Most research in the field of electrochromism over the past 2 decades has been focused on transition-metal oxides $(7,9)$ ECDs incorporating transition-metal oxides as active layers, however, have been typically prepared using complicated vacuum evaporation processes and high-temperature sintering processes; these ECDs generally feature low coloration efficiencies and slow response times, which inevitably limit their commercial and industrial applications. Therefore, the development of solution-processable organic materialsincluding polypyrrole $(10,11)$ polyaniline $(12)$, polythiophenes (13-18) and other chromophoric molecules $(19,20)$-has garnered more attention for the preparation of ECDs be-

* Corresponding author. Telephone: +886-2-23660739 (K.-C.H.), +886-2-27898000, ext. 70 (C.-W.C.). Fax: +886-2-23623040 (K.-C.H.), +886-2-27826680 (C.-W.C.) E-mail: kcho@ntu.edu.tw (K.-C.H.), gchu@gate.sinica.edu.tw (C.-W.C.) Received for review August 26, 2009 and accepted November 5, 2009

${ }^{+}$Department of Chemical Engineering, National Taiwan University.

${ }^{*}$ National Tsing Hua University.

${ }^{\perp}$ Institute of Polymer Science and Engineering, National Taiwan University.

§ Taiwan Textile Research Institute.

" Academia Sinica.

\# National Chiao-Tung University.

DOI: $10.1021 / a m 900573 q$

- 2009 American Chemical Society cause they possess several advantageous properties: large coloration efficiencies, ease of color tuning, high electrochromic contrast, and rapid response times. Although polypyrrole exhibits good conductivity and high stability in its oxidized form, it suffers from undesired $\alpha-\beta$ and $\beta-\beta$ couplings during polymerization, which deteriorate its properties (21). Furthermore, although polyaniline stands out for its ability to form conductive materials at relatively low cost, it can yield toxic products upon degradation (22) because of the presence of benzidine moieties in its polymer backbone. Therefore, among these candidate conjugated polymers, polythiophene and its derivatives have been investigated extensively because of their relative stability and environmentally friendly properties (23-27).

Poly(3-alkylthiophene)s (P3ATs) are commonly applied in ECDs (28-31). For example, an all-thiophene ECD fabricated through electrochemical deposition was reported by Ribeiro et al. (32); in addition, poly(3-methylthiophene) is a promising electrochromic material because of its response time of a few milliseconds and cyclability of more than $10^{5}$ cycles (33). Nevertheless, the high oxidation potential of P3ATs leads to irreversible overoxidation of the polymer during the electrodeposition process. Although thiophene oligomers can be polymerized electrochemically at lower potentials than the parent monomer, the resulting polymers exhibit below-average conjugation lengths. Therefore, oxidative chemical polymerization is, at present, an important means of synthesizing high-molecular-weight P3ATs exhibiting solution processability. Furthermore, the oxidative chemi- 


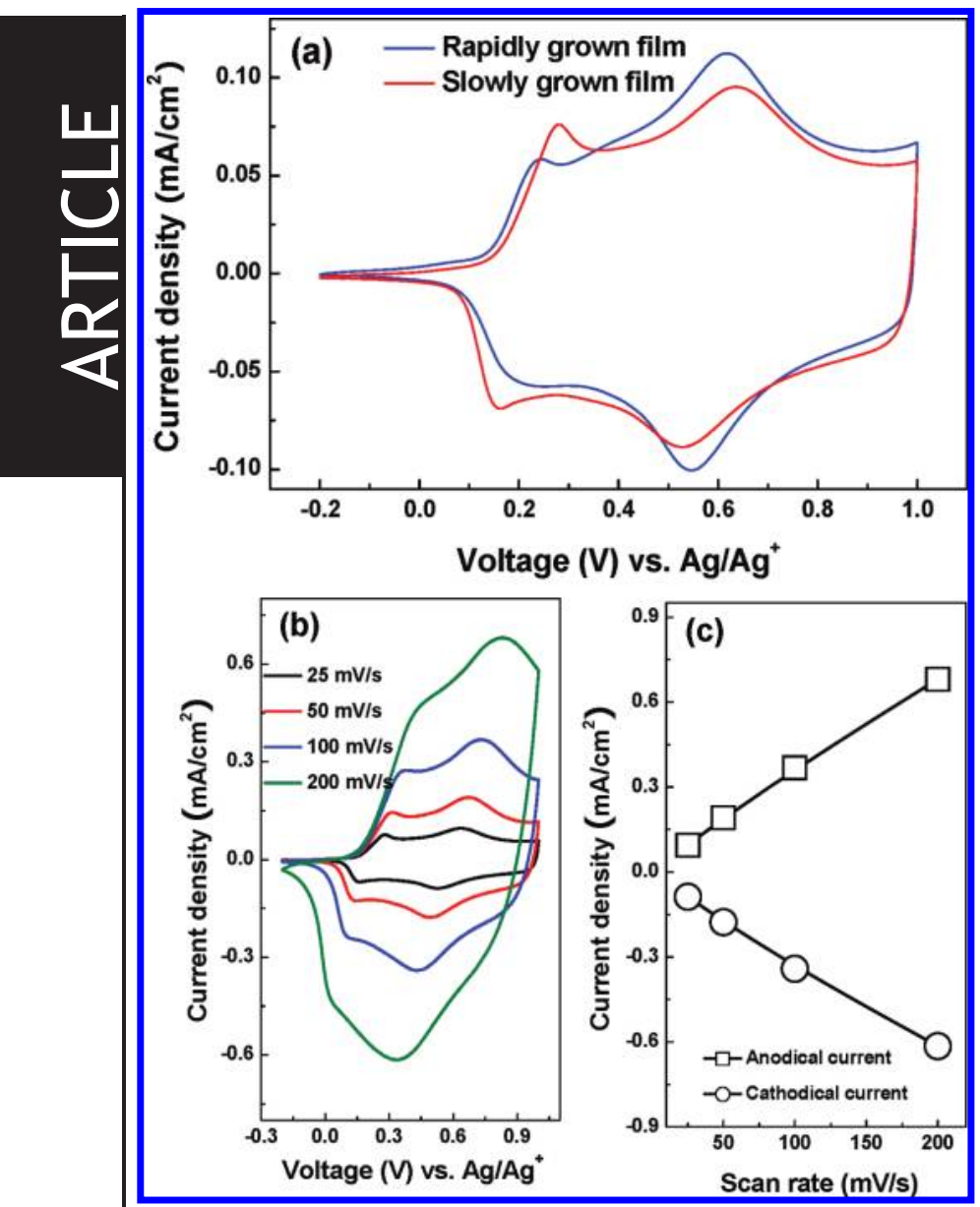

FIGURE 1. (a) Cyclic voltammograms of P3HT prepared using rapidand slow-growth methods $\left[\mathrm{vs} \mathrm{Ag} / \mathrm{Ag}^{+}(\mathrm{ACN})\right]$ in $0.1 \mathrm{M} \mathrm{LiClO}_{4} /$ cellulose acetate nitrate. (b) Cyclic voltammograms of the P3HT films at various potential scan rates. (c) Plots of the current densities versus the scan rates for the P3HT films.

cal polymerization can also control the polymer regioregularity (RR) on the molecular nanostructure, leading to improved optical and electronic properties. Therefore, P3ATs are formed more readily through solution processing rather than electrodeposition.

Regioregular poly(3-hexylthiophene)s (RR-P3HTs) exhibit good self-organizing properties, forming crystalline structures suitable for electronic applications. The electronic transport and optical properties of P3HTs are critically affected by solvent annealing (34-36) and heat treatment (37), which varies the field-effect mobilities and absorption of the materials through higher degrees of $\pi-\pi$ stacking. Sirringhaus et al. fabricated P3HT-based transistors exhibiting mobilities greater than $0.1 \mathrm{~cm}^{2} \mathrm{~V}^{-1} \mathrm{~s}^{-1}$ by controlling the growth rate of P3HT (38). In addition, Yang et al. reported very efficient plastic solar cells based on P3HT and $[6,6]$ phenyl- $\mathrm{C}_{61}$-butyric acid methyl ester; controlling the growth rate of the active layer enhanced the device efficiency significantly (39-41). Although many studies have focused on improving the performance of thin-film transistors and solar cells by controlling the growth of P3HT, the ECDs incorporating P3HT have received much less attention. In this paper, we reveal that controlling the solvent evaporation rate from solution to the solid state can significantly enhance

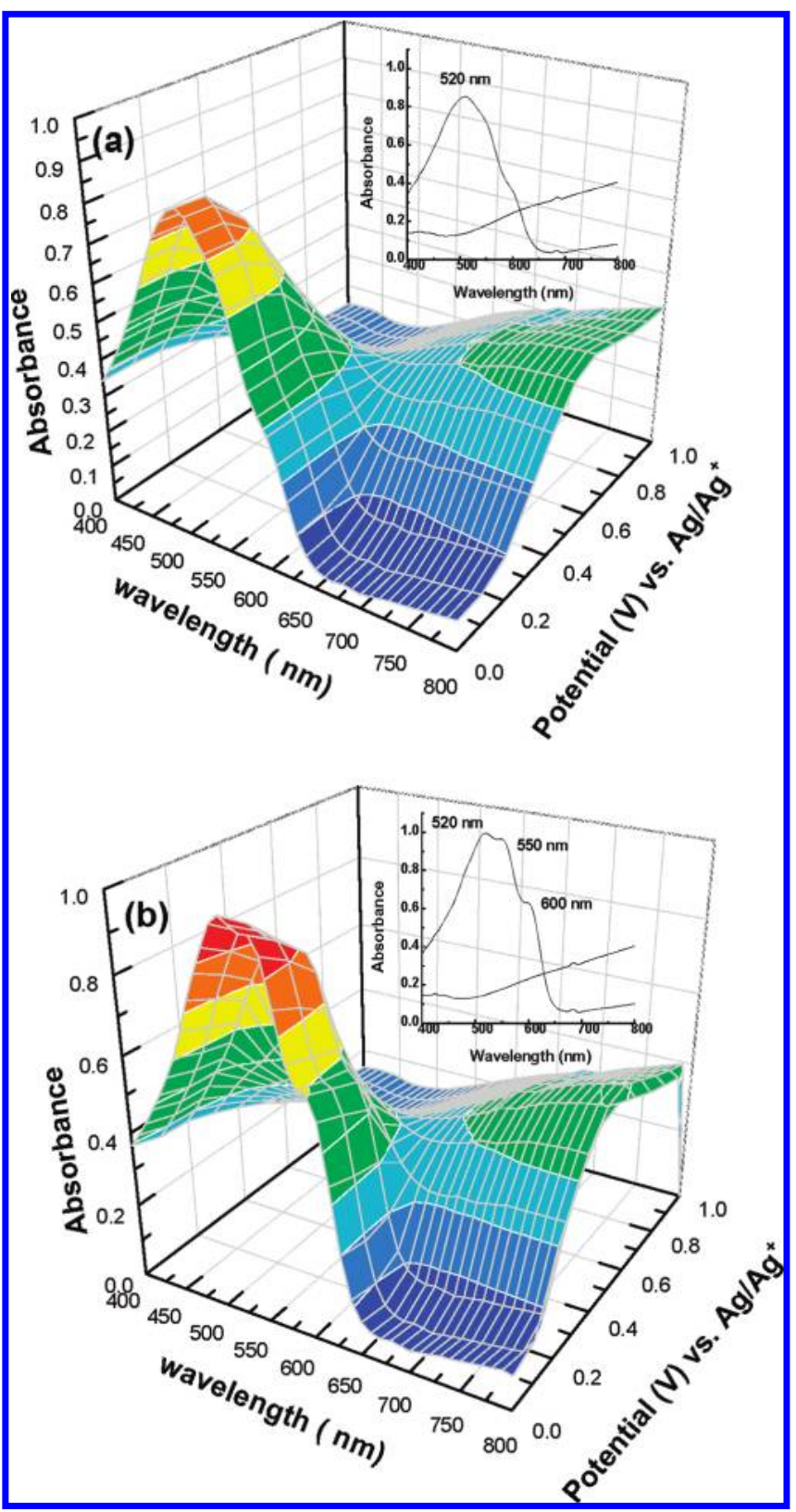

FIGURE 2. Three-dimensional spectroelectrochemical surfaces of the (a) rapidly and (b) slowly grown films. Spectra were recorded at 100 $\mathrm{mV}$ increments between 0 and $1 \mathrm{~V}$ [vs Ag/ $\left./ \mathrm{Ag}^{+}(\mathrm{ACN})\right]$.

the electrochromic contrast of P3HT. We found that both the electron-transfer resistance and field-effect mobility could be increased by an order of magnitude, leading to shorter switching times and higher coloration efficiencies. We prepared these electrochromic films through a solution-based process, allowing large-area devices to be obtained at relatively low cost.

\section{EXPERIMENTAL SECTION}

Chemicals. Poly(3-hexylthiophene) (P3HT) was purchased from Rieke Metals. Its regioregularity, weight-average $\left(M_{\mathrm{w}}\right)$ and number-average $\left(M_{\mathrm{n}}\right)$ molecular weights, and polydispersity index (PDI) were $93 \%, 3.7 \times 10^{4}, 2.5 \times 10^{4}$, and 1.48 , respectively. The optically transparent indium-tin oxide (ITO; $R_{\mathrm{sh}}=20 \Omega \mathrm{sq}^{-1}$ ) substrates were supplied by RiTdisplay Corp. (Hsinchu Industrial Park, Taiwan).

Polymer Thin-Film Deposition. Prior to deposition, P3HT was dissolved in 1,2,4-trichlorobenzene (TCB) and then stirred 


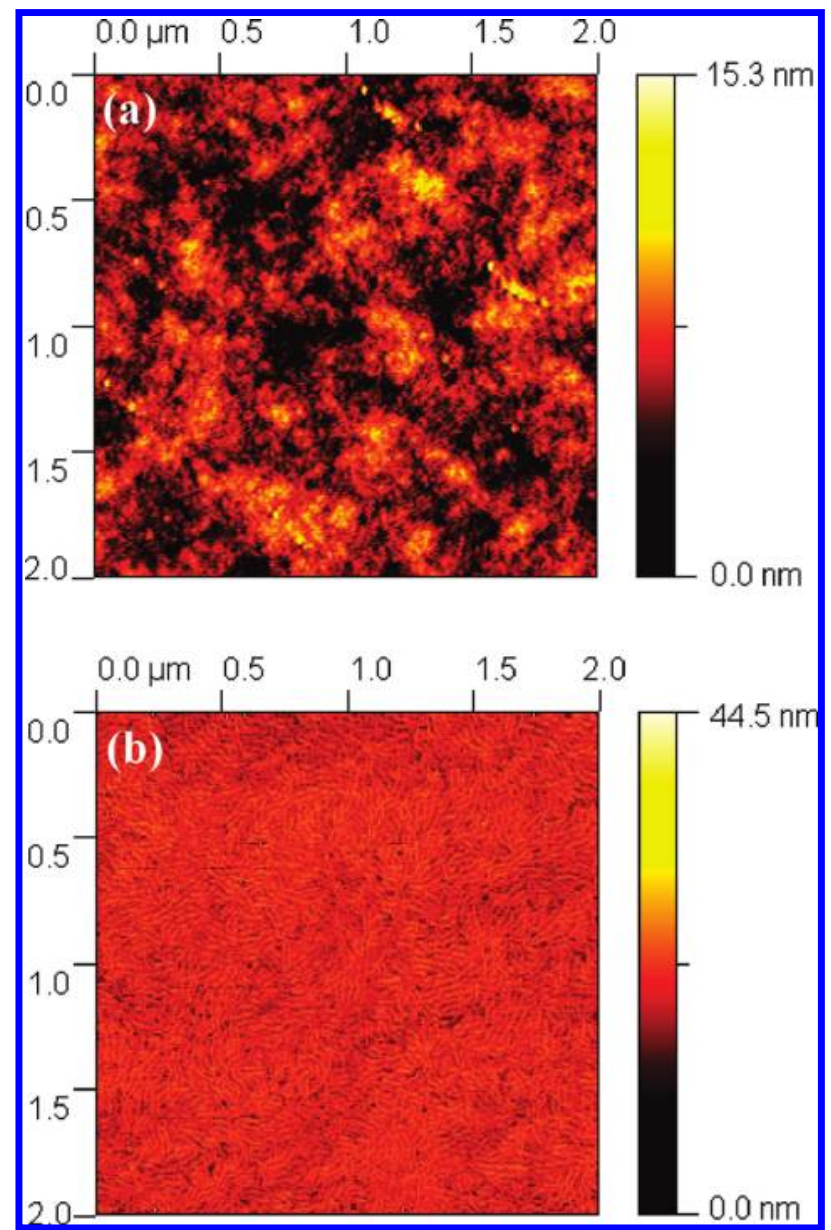

FIGURE 3. AFM images of P3HT films prepared using the (a) rapid and (b) slow-growth methods.

for $12 \mathrm{~h}$ at $50{ }^{\circ} \mathrm{C}$. After the polymer solution cooled, the slowly grown films were obtained by spin-coating the polymer solution on ITO glass at $600 \mathrm{rpm}$ for $50 \mathrm{~s}$. Every sample was coated with one layer. Spin coating at $600 \mathrm{rpm}$ left the films wet, and they were then dried in covered glass Petri dishes within $30 \mathrm{~min}$ The rapidly grown film was heated at $150{ }^{\circ} \mathrm{C}$ for $5 \mathrm{~s}$. The thicknesses of the films were $200-210 \mathrm{~nm}$, and the active area was $2 \times 2 \mathrm{~cm}^{2}$. The whole deposition process were performed in a nitrogen environment inside a glovebox. The temperature and $\mathrm{O}_{2}$ and $\mathrm{H}_{2} \mathrm{O}$ concentrations inside the glovebox were controlled at $25^{\circ} \mathrm{C}$ and 0.1 and $0.1 \mathrm{ppm}$, respectively.

Fabrication of Field-Effect Transistors (FETs). A heavily doped p-type silicon $\left(\mathrm{p}^{+}-\mathrm{Si}\right)$ wafer and a 300-nm thermally oxidized $\mathrm{SiO}_{2}$ film were used as the gate and dielectric, respectively, for P3HT-based FETs. The substrates were cut into 1.5 $\mathrm{cm} \times 1.5 \mathrm{~cm}$ pieces through mechanical scribing. Prior to deposition, the substrates were cleaned with acetone and isopropyl alcohol in an ultrasonic bath, followed by UV-ozone cleaning for $15 \mathrm{~min}$. The semiconductor layer P3HT was prepared by spin-coating a solution of P3HT ( $2 \mathrm{wt} \%)$ in TCB at $2500 \mathrm{rpm}$ and with a thickness of ca. 110-130 nm. Finally, the 50-nm-thick gold film was thermally evaporated onto the F8T2 film through a shadow mask to form source/drain electrodes.

Characterization of Polymer Films. Cyclic voltammetry (CV) was performed using a three-electrode cell with $0.1 \mathrm{M} \mathrm{LiClO}_{4} /$ acetonitrile (ACN) and ITO glass as the working electrodes, a platinum sheet as the counter electrode, and nonaqueous Ag/ $\mathrm{Ag}^{+}$(containing $0.01 \mathrm{M} \mathrm{AgNO}_{3}$ and $0.1 \mathrm{M} \mathrm{TBAClO}_{4}$ in $\mathrm{ACN}$ ) as the reference electrode. Spectroelectrochemical data were recorded using a Shimadzu UV-1601PC spectrophotometer. Surface morphologies were observed using an atomic force

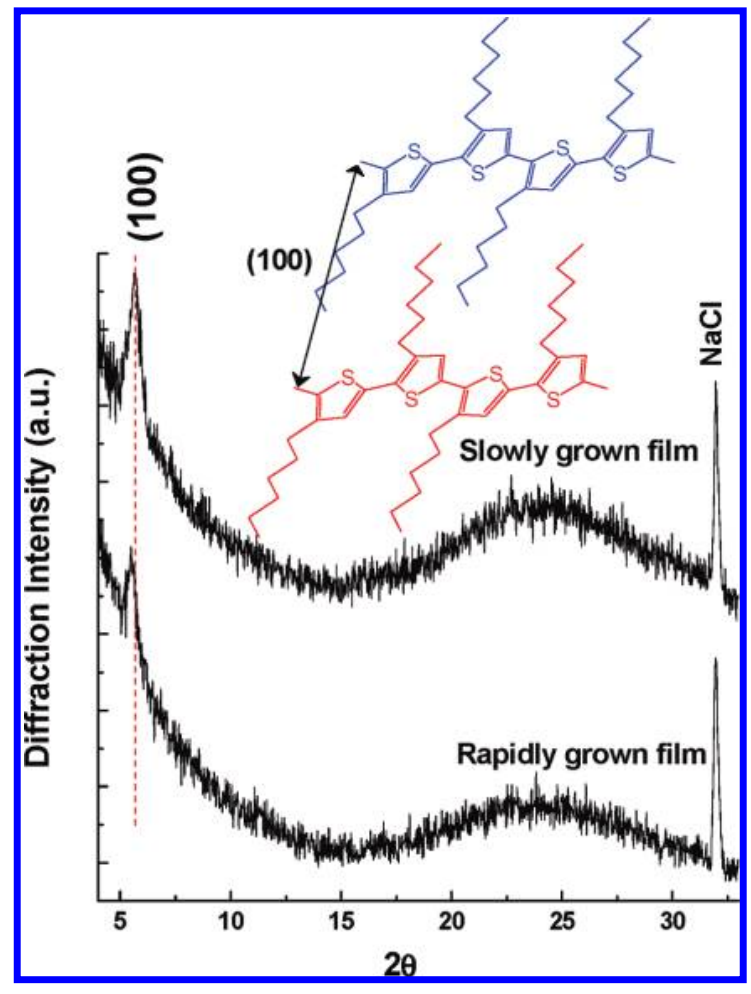

FIGURE 4. XRD spectra of P3HT films prepared with and without solvent annealing.

microscope (Digital Instruments NS 3a controller with a D3100 stage). XRD analyses were performed using a Philips X'Pert/ MPD instrument. For electrochemical impedance spectroscopy (EIS) analysis, the P3HT electrodes were characterized using a three-electrode system (the potentiostat mentioned above) equipped with an FRA2 module in the presence of $1.0 \mathrm{mM}$ redox couples and $0.1 \mathrm{M} \mathrm{LiClO}_{4}$ in an aqueous solution. The impedance spectra were recorded at the formal potential of the redox couple in the frequency ranging from 100 to $10000 \mathrm{~Hz}$. Colorimetry measurements were performed using a Minolta CS100 Chroma Meter; the sample was illuminated from behind using a D50 (5000 K) light source. A background measurement was taken from blank ITO glass in an electrolyte solution held in a standard quartz cuvette.

\section{RESULTS AND DISCUSSION}

Figure 1 a displays cyclic voltammograms of P3HT, prepared using rapid- and slow-growth methods, recorded in $0.1 \mathrm{M} \mathrm{LiClO}_{4} / \mathrm{ACN}$. The behavior of these two sets of films was very similar, with two coupled redox peaks appearing between -0.2 and $1.0 \mathrm{~V}$. These multiple signals were due to the sequential reduction of bipolaronic and polaronic charge carriers (42). Parts b and c of Figure 1 display the cyclic voltammograms and variations of the current densities of the slowly grown films upon an increase of the scan rate up to $400 \mathrm{mV} \mathrm{s}^{-1}$. A linear relationship existed between the peak current and the scan rate, indicating that the electroactive polymer films adhered well to the ITO electrodes and that the electrochemical processes were reaction-controlled. The current was not limited by the diffusion of counterions. Moreover, the slight increases in the anodic peak potentials suggested that the redox processes were not reversible; instead, they followed a quasi-reversible mechanism.

Figure 2 presents the optoelectrochemical spectral series obtained for rapidly and slowly grown films while changing 

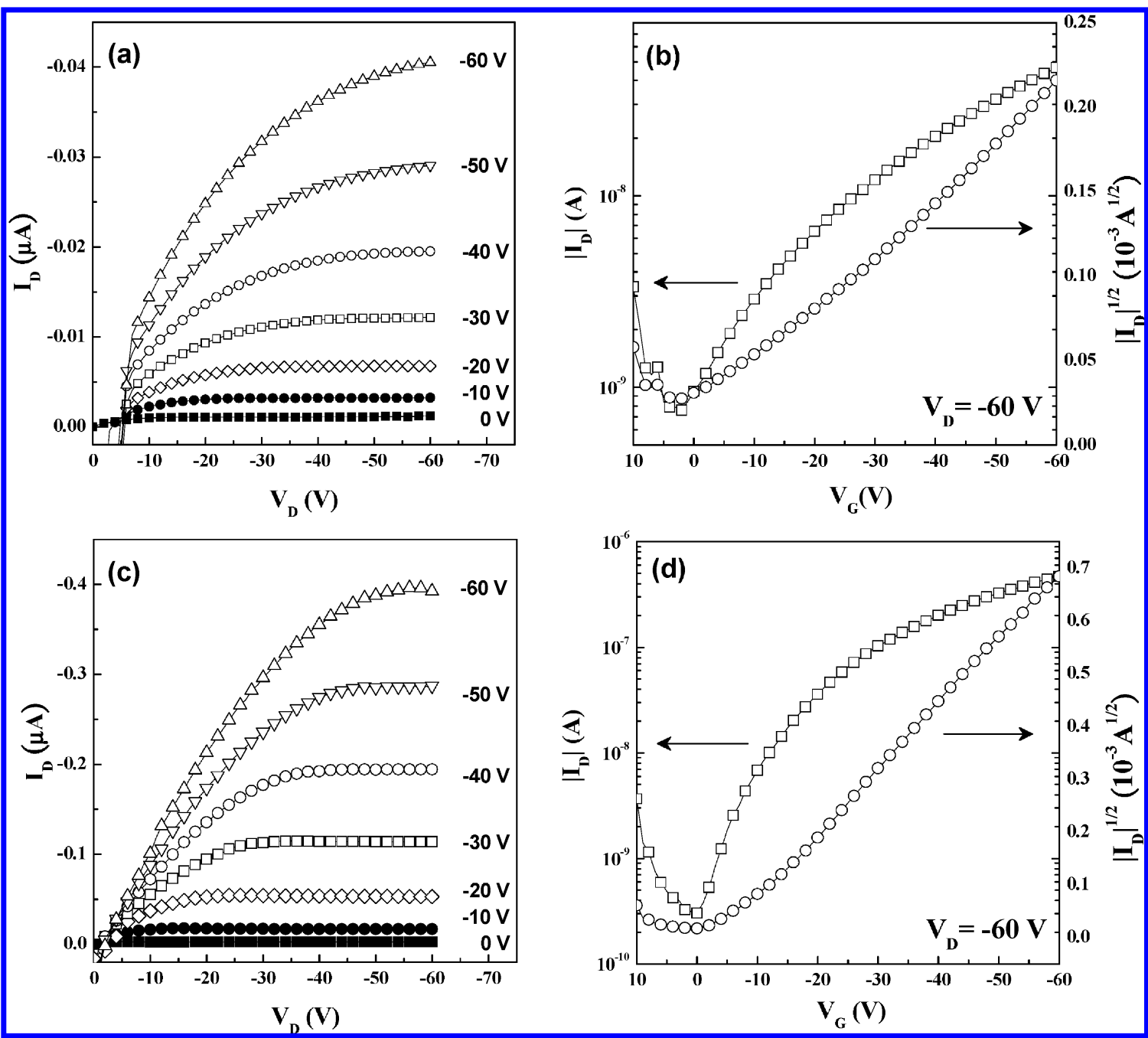

FIGURE 5. Output at different gate voltages $\left(V_{\mathrm{G}}\right)$ and transfer characteristics in the saturation regime at a constant source/drain voltage $\left(V_{\mathrm{DS}}=-60 \mathrm{~V}\right)$ for FETs incorporating the $(\mathrm{a}$ and $\mathrm{b})$ rapidly and (c and d) slowly grown films.
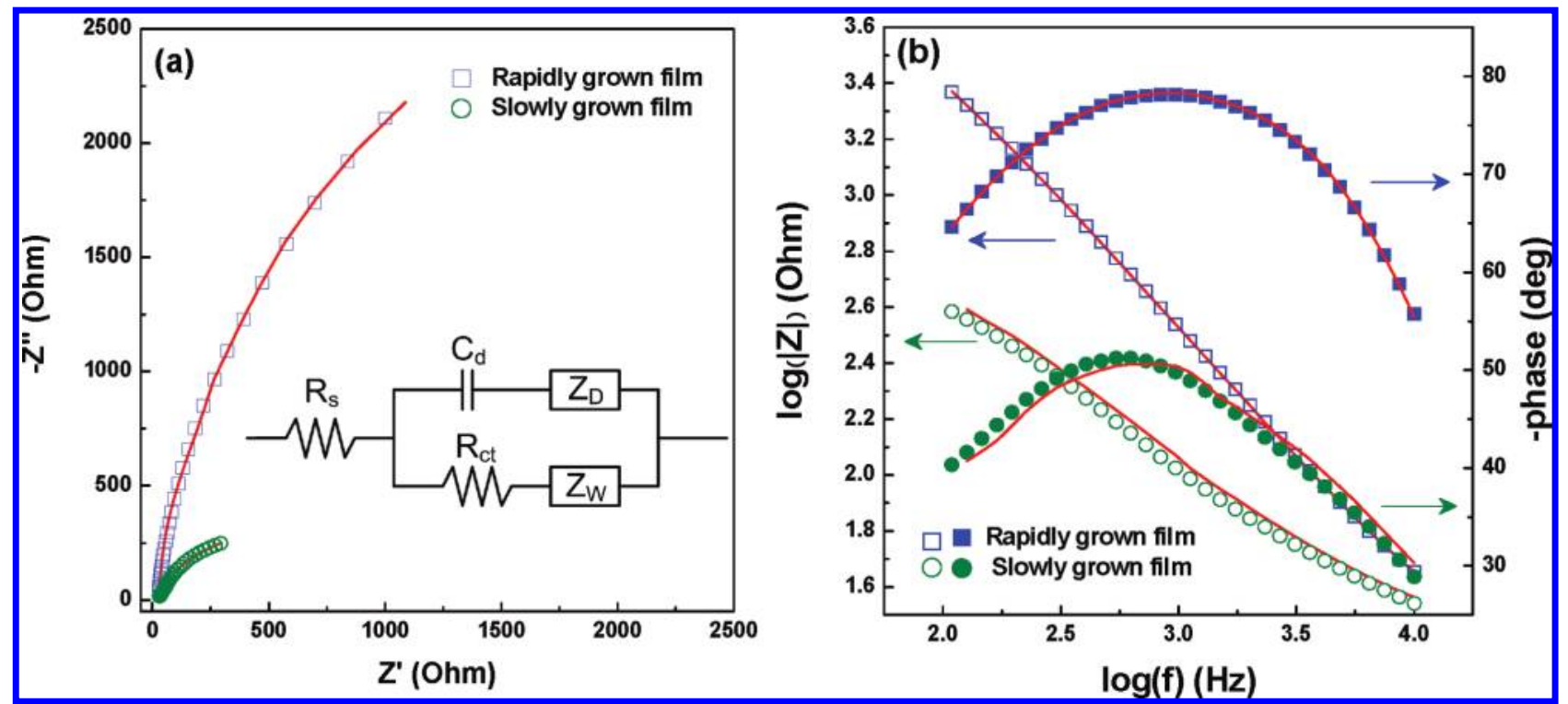

FIGURE 6. (a) Nyquist and (b) Bode plots providing both experimental (dots) and fitting (lines) data.

from the reduced state to the fully oxidized state. The features in these two sets of spectra are very similar. Stepwise oxidation of the polymer led to a reduction in the absorbance throughout the visible region, as the color changed from a purple state (reduced form) to a pale-blue state (oxidized form). Both the rapidly and slowly grown 

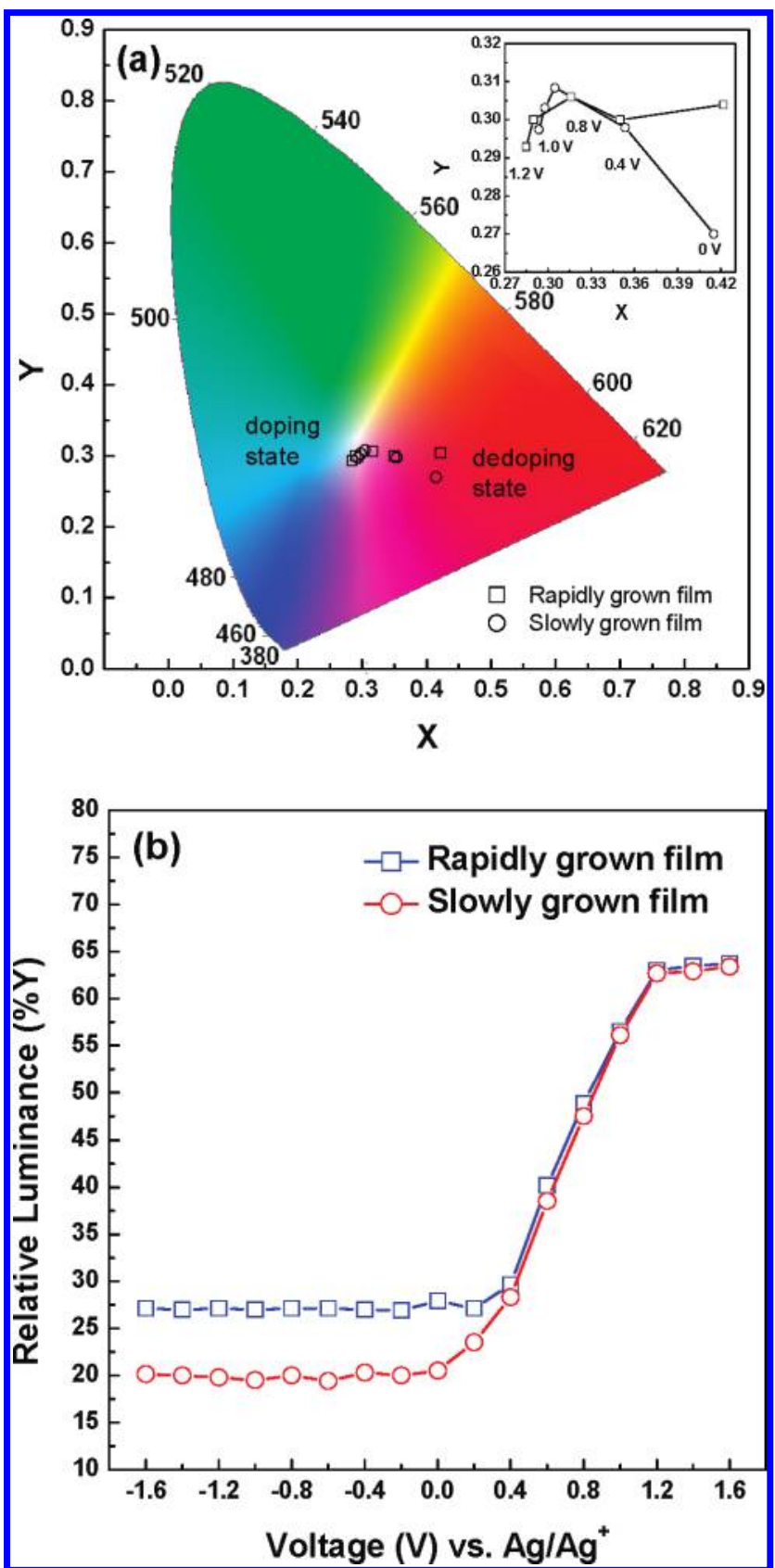

FIGURE 7. (a) CIE $1931 x y$ chromaticity diagram for the rapidly and slowly grown P3HT films as a function of the applied potential. (b) Relative luminance ( $\%$ Y) for the rapidly and slowly grown P3HT films at applied potentials ranging from -1.6 to $+1.6 \mathrm{~V}[\mathrm{vs} \mathrm{Ag/}$ $\left.\mathrm{Ag}^{+}(\mathrm{ACN})\right]$.

P3HT films underwent obvious bleaching when the applied potential was more positive than $0.3 \mathrm{~V}$, consistent with the anodic peak potential in Figure 1. The spectrum of the slowly grown film, however, reveals a larger absorbance at $520 \mathrm{~nm}$ and another two shoulders located at 550 and $600 \mathrm{~nm}$ (inset to Figure 2b). Because the thicknesses of each film were similar (ca. $250 \mathrm{~nm}$ ), we attribute the change in the peak absorption wavelength during solvent annealing to the improved $\pi-\pi^{*}$ stacking, leading to increased interchain interactions between P3HT chains (43-45). The increased degree of interchain interaction among the P3HT chains after solvent annealing resulted in stronger absorbance ( 1.04 for slowly grown film; 0.85 for rapidly grown film) and two distinguishable shoulder signals, leading to a significantly broadened spectrum. As a result, the electrochromic contrast in the visible region was greater for the slowly grown polymers, making them better candidates for use in electrochromic applications.

Polymer crystallization from solution into a thin film is an exothermic process that can be affected by the solvent evaporation rate (46). The film morphology of P3HT films can be visualized using tapping-mode atomic force microscopy (AFM). Figure 3 displays the surface topography of the polymer films processed with and without solvent annealing. Two features are evident: (1) The surface processed with solvent annealing was significantly rougher [root-meansquare (rms) surface roughness: $4.7 \mathrm{~nm}$ ] than that obtained without solvent annealing [(rms) surface roughness: $1.3 \mathrm{~nm}$ ]. (2) Highly ordered fibrillar crystalline domains of P3HT (domain size: $22 \mathrm{~nm}$ ) are clearly visible in the images of the slowly grown film; they are absent in the case of the rapidly grown film. We assign these fibrillar features to domains of P3HT crystallites originating from highly tight stacks of several polymer chains. Recently, Brinkmann et al. investigated the semicrystalline structure of P3HT and found a lamellar periodicity of ca. $28 \mathrm{~nm}$; this long-range order includes the crystalline region as well as disordered zones that harbor structural defects, such as chain ends and folds and tie segments (47). Our observations for these polymer films are consistent with their findings. Thus, reducing the solvent evaporation rate can provide highly ordered P3HT chains, consistent with our optical absorption measurements.

AFM observations are limited only to the surface of the film; to obtain the overall crystalline structure of P3HT films, we performed further studies using X-ray diffraction (XRD). Both films exhibited an intense (100) diffraction peak (Figure 4), implying that they featured very highly ordered edge-on hexyl side chains. The ordered structure was formed from parallel stacks of P3HT main chains separated by regions filled with alkyl side chains (inset to Figure 4). The $2 \theta$ angle of the maximum diffraction peak of the slowly grown film $\left(5.69^{\circ}\right)$ was greater than that of the rapidly grown film $\left(5.49^{\circ}\right)$. Substitution of these data into the Bragg equation yields a mean interlayer spacing for the slowly grown film of $15.5 \AA$, which is $0.6 \AA$ less than that of rapidly grown film (16.1 $\AA$ ). Closer P3HT chains suggest a lower resistance to the hopping of carriers between P3HT backbones (48). Our AFM and XRD analyses provide sufficient evidence suggesting that strong interlayer interactions within the P3HT were realized during the solvent-annealing process, leading to a larger electrochromic contrast.

To determine the relationship between the molecular ordering and the electrical characteristics, we used a topcontact FET geometry to measure the field-effect mobilities of the P3HT films. Parts a,b and c,d of Figure 5 display the output and transfer characteristics of P3HT-based FETs fabricated using rapid- and slow-growth methods, respectively. We calculated the field-effect mobility of each transistor in the saturation regime $\left(V_{\mathrm{DS}}=-60 \mathrm{~V}\right)$ by plotting the 


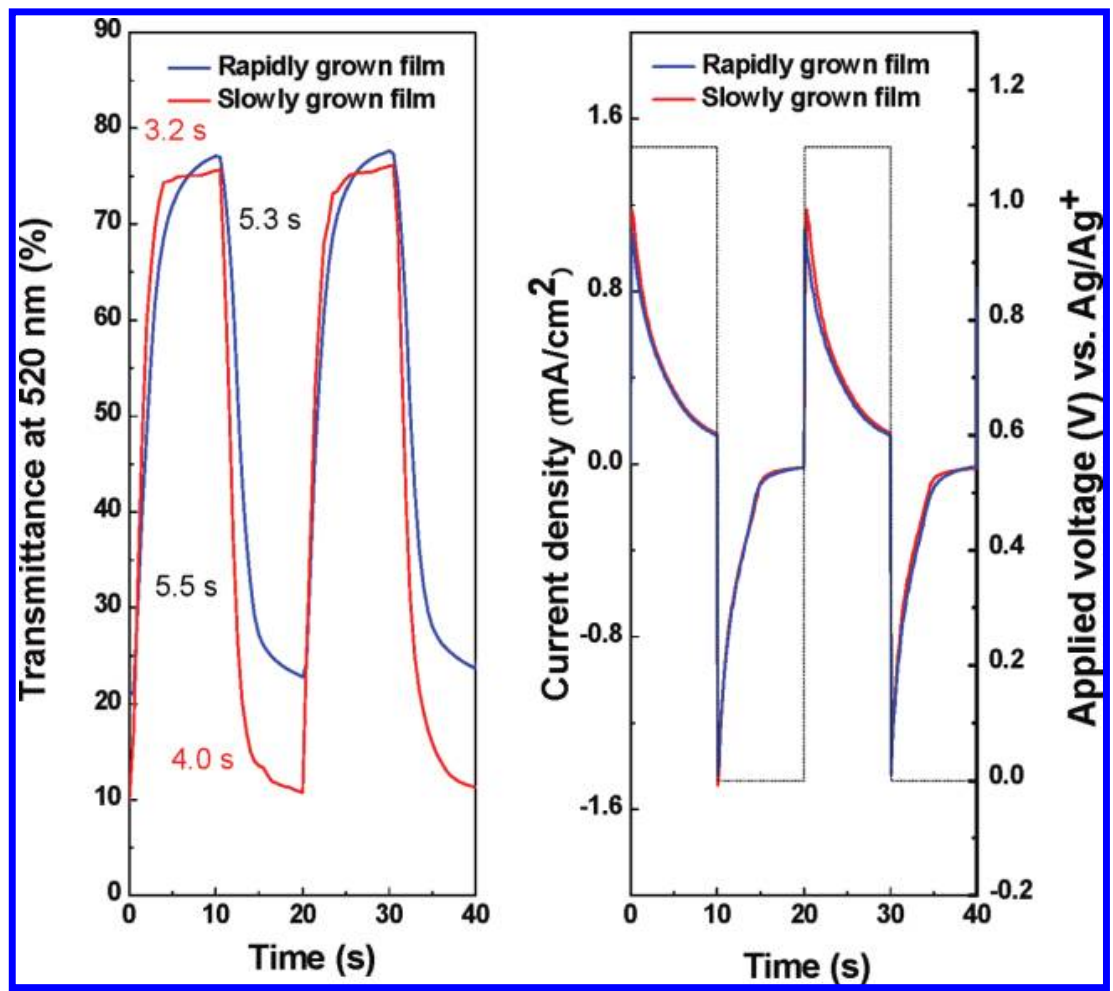

FIGURE 8. Optical transmittance changes and current densities monitored for the rapidly and slowly grown films at $520 \mathrm{~nm}$, stepped between 0.0 and $1.1 \mathrm{~V}[\mathrm{vs} \mathrm{Ag/Ag}(\mathrm{ACN})]$. The dotted line represents the applied voltage.

square root of the drain current against the gate voltage and fitting the data to the following equation (49):

$$
I_{\mathrm{DS}}=\frac{W C_{\mathrm{i}}}{2 L} \mu\left(V_{\mathrm{GS}}-V_{\mathrm{T}}\right)^{2}
$$

with $C_{\mathrm{i}}$ equal to $1.0 \times 10^{-8} \mathrm{~F} \mathrm{~cm}^{-2}, W$ equal to $2 \mathrm{~mm}$, and $L$ equal to $100 \mathrm{~mm}$. The hole mobility (up to $6.5 \times 10^{-3} \mathrm{~cm}^{2}$ $\mathrm{V}^{-1} \mathrm{~S}^{-1}$ ) and on/off ratios (up to $1 \times 10^{4}$ ) of the slowly grown P3HT were higher (by 1 order of magnitude) than those of the rapidly grown sample. Because the P3HT samples had the same molecular weight, the higher mobility of the slowly grown material must be due to the structural ordering in the film, providing a more favorable morphology, as revealed by AFM and XRD measurements.

To investigate the kinetics of the electron transfer at the polymer-solution interface, we characterized the polymer films using EIS. Figure 6a displays the impedance spectra of the polymer films characterized under $1.0 \mathrm{mM} \mathrm{K}_{4} \mathrm{Fe}(\mathrm{CN})_{6}$, $\mathrm{K}_{3} \mathrm{Fe}(\mathrm{CN})_{6}$, and $0.1 \mathrm{M} \mathrm{LiClO}_{4}$ as the supporting electrolyte. We fit the EIS data with the equivalent circuit (47) presented in the inset to Figure 6a. In the equivalent circuit, $R_{\mathrm{S}}$ is the solution resistance, $R_{\mathrm{ct}}$ is the charge-transfer resistance due to electron transfer at the polymer-solution interface, $Z_{\mathrm{w}}$ is the infinite-length Warburg diffusion impedance due to diffusion of the redox couple in the solution, $C_{\mathrm{d}}$ is the electronic capacitance of the polymer film, and $Z_{\mathrm{d}}$ is the finite-length Warburg diffusion impedance due to diffusion of charge-compensating counterions in the polymer film. The fitting results are presented in Figure $6 a, b$, where the solid lines represent the modeling results obtained by fitting the dotted experimental data. The fitted results suggest that the values of $R_{\mathrm{ct}}$ of the rapidly and slowly grown films were
5960 and $505 \Omega$, respectively. The smaller value of $R_{\mathrm{ct}}$ of the slowly grown film resulted from its highly ordered structure, which provided a larger charge mobility, leading to a lower resistance at the polymer-electrolyte interface. The amorphous structure of the rapidly grown film, however, resulted in poor charge transport, leading to a larger value of $R_{\mathrm{ct}}$. We obtained the rate constant of the electron transfer $\left(k_{0}\right)$ by using the following equation (50):

$$
k_{0}=\frac{R T}{n^{2} F^{2} R_{\mathrm{ct}} A C}
$$

where $A$ is the area of the electrode, $C$ is the bulk concentration of the redox couple, and the other symbols have their usual electrochemical meanings. Using the known values of $R_{\mathrm{ct}}$, we calculated the values of $k_{0}$ for the rapidly and slowly grown films as $4.5 \times 10^{-5}$ and $5.3 \times 10^{-4} \mathrm{~cm} \mathrm{~s}^{-1}$, respectively. Thus, the improved crystallinity of P3HT after solvent annealing resulted in not only a larger mobility but also a decreased value of $R_{\mathrm{ct}}$, leading to a larger value of $k_{0}$.

We employed colorimetry techniques to study the optical properties of the P3HT films grown using different methods and, thereby, precisely define the color changes occurring during redox reaction. The inset of Figure 7 a reveals that, as the potential increased and the polymers became doped, the $x$ coordinate decreased and the $y$ coordinate also generally decreased. Figure 7a displays the CIE 1931 Yxy color space for the rapidly and slowly grown films; these polymers switched from orange and purple neutral states, respectively, at $0 \mathrm{~V}$ to pale-blue oxidized states at $1.2 \mathrm{~V}$. Compared with the rapidly grown film, the slowly grown film exhibited a deeper color in its neutral state $(0 \mathrm{~V})$. This deeper color resulted from the greater absorbance and the two shoulder 
signals located at 550 and $600 \mathrm{~nm}$ in Figure 2. In their oxidized states, however, the films exhibited almost the same optical properties, leading to a larger contrast for the slowly grown film.

The potential dependence of the relative luminance offers a perspective on the transmissivity of a material as it relates to the human eye's perception of transmittance over the entire visible spectrum as a function of doping on a single curve. Figure $7 \mathrm{~b}$ displays the relative luminance $\left(\begin{array}{ll}\% & Y\end{array}\right)$ dependence on the applied potential for the rapidly and slowly grown films. As expected for this cathodically coloring polymer, the value of $\% Y$ increased upon oxidation from 27 to $63.7 \%$ for the rapidly grown film and from 19.5 to $63.4 \%$ for the slowly grown film. The purple/orange color of the slowly grown film reveals a smaller relative luminance in the neutral state in comparison with that of the rapidly grown film, leading to a larger contrast for the former. In terms of their use as electrochromic materials, the polymer films prepared using the slow-growth method are better candidates for electrochromic applications.

Figure 8 presents the transmittance (at $520 \mathrm{~nm}$ ) and current density during cyclic potentiostatic switching (first two cycles) for P3HT films having a size of $2 \times 2 \mathrm{~cm}^{2}$. The samples were darkened (bleached) through application of a potential of $1.1 \mathrm{~V}(0 \mathrm{~V})$ with a switching interval of $10 \mathrm{~s}$ in $0.1 \mathrm{M} \mathrm{LiClO}_{4} / \mathrm{ACN}$. The optical contrast $(\Delta \% T)$ was quite high for the slowly grown film as a result of the self-organization effect, consistent with our optoelectrochemical findings; the oxidized film was $75.5 \%$ transmissive while the reduced film was $10.7 \%$ transmissive, resulting in a value of $\Delta \% T$ of $64.8 \%$, which was larger than that of the rapidly grown film $(54.2 \%)$. The switching times for maximum electrochromic contrast during bleaching (darkening) were $5.3 \mathrm{~s}(5.5 \mathrm{~s})$ for the rapidly grown film and $3.2 \mathrm{~s}(4.0 \mathrm{~s})$ for the slowly grown film. In addition, from Figure 8b, we calculated the charge injected/extracted per unit area, allowing us to determine the coloration efficiency using the equation

$$
\eta=\frac{\Delta \mathrm{OD}\left(\lambda_{\max }\right)}{Q}
$$

where $Q$ is the injected/extracted charge per unit electrode area $\left(\mathrm{C} \mathrm{cm}^{-2}\right)$ and $\Delta O D$ is the change in absorbance at $520 \mathrm{~nm}$ during a redox step. The calculated coloration efficiency of the slowly grown film was $293.5 \mathrm{~cm}^{2} \mathrm{C}^{-1}$, somewhat higher than that of the rapidly grown film $\left(182.6 \mathrm{~cm}^{2} \mathrm{C}^{-1}\right)$. As described above, the crystalline structure of the slowly grown film was responsible for its larger charge mobility and lower value of $R_{\mathrm{ct}}$ at the polymer film-electrolyte interface. In the cyclic voltammograms in Figure 1, the linear relationship between the peak current and scan rate indicates that the electrochemical processes are reaction-controlled and not controlled by the diffusion of counterions. Therefore, a larger charge mobility and lower value of $R_{\mathrm{ct}}$ within the polymer film can facilitate the electrochemical reaction, leading to a faster switching time. Note that the electrochromic coloration efficiency is affected by several other factors, such as the conformational structure (51, 52), morphology (53), and doping level (54), which are governed by the processing method and condi- tions. In addition to the lower charge-transfer resistance at the film-electrolyte interface and the lower internal resistance, we believe that these factors are also responsible for the higher coloration efficiency.

In summary, we have obtained a deeper understanding of how the self-organization of a polymer influences its electrochromic properties. We observed polymer ordering of P3HT using both XRD and AFM. UV-vis spectra and the CIE color space revealed that superior polymer stacking led to a larger optical contrast. FET characteristics and EIS measurements revealed that the P3HT film prepared through solvent annealing (or slow growth) featured a higher charge mobility and lower resistance, leading to an improved electrochromic coloration efficiency and faster response time.

Acknowledgment. We thank the National Science Council, Taiwan (NSC 98-2221-E-001-002-), and Academia Sinica, Taiwan, for financial support. This work was also partially supported by the Taiwan Textile Research Institute, Tucheng City, Taipei County, Taiwan.

\section{REFERENCES AND NOTES}

(1) Andersson, P.; Forchheimer, R.; Tehrani, P.; Berggren, M. Adv. Funct. Mater. 2007, 17, 3074

(2) Nishikitani, Y.; Uchida, S.; Asano, T.; Minami, M.; Shirna, S.; Kai, K.; Kubo, T. I. Phys. Chem. C 2008, 112, 4372.

(3) Shim, G. H.; Han, M. G.; Sharp-Norton, J. C.; Creager, S. E.; Foulger, S. H. L. Mater. Chem. 2008, 18, 594.

(4) Tehrani, P.; Hennerdal, L. O.; Dyer, A. L.; Reynolds, J. R.; Berggren, M. I. Mater. Chem. 2009, 19, 1799.

(5) Monk, P. M. S.; Mortimer, R. J.; Rosseinsky, D. R. Electrochromism and Electrochromic Devices: Cambridge University Press: Cambridge, U.K., 2007

(6) Dyer, A. L.; Reynolds, J. R. In Handbook of Conducting Polymers, 3rd ed.; Skotheim, T. A., Reynolds, J. R., Eds.; CRC Press: Boca Raton, FL, 2007; Vol. 1, Chapter 20.

(7) Wang, J. M.; Khoo, E.; Lee, P. S.; Ma, J. I. Phvs. Chem. C 2008, $112,14306$.

(8) Ferreira, F. F.; Avendano, E. I. Phys. Chem. C 2007, 111, 16608.

(9) DeLongchamp, D. M.; Hammond, P. T. Adv. Funct. Mater. 2004, 14,224

(10) Wang, X.; Smela, E. I. Phys. Chem. C 2009, 113, 369

(11) Ak, M.; Gacal, B.; Kiskan, B.; Yagci, Y.; Toppare, L. Polymer 2008, 49, 2202

(12) Xia, X. H.; Tu, J. P.; Zhang, J.; Wang, X. L.; Huang, H. Nanotechnologv 2008, 19, 465701.

(13) Bhandari, S.; Deepa, M.; Srivastava, A. K.; Kant, R. L. Mater. Chem. 2009, 19, 2336.

(14) Dyer, A. L.; Grenier, C. R. G.; Reynolds, J. R. Adv. Funct. Mater. 2007, 17, 1480 .

(15) Algi, F.; Cihaner, A. Orq. Electron. 2009, 10, 453.

(16) Çetin, C. A.; Balan, A.; Durmus, A.; Gũnbas, G.; Toppare, L. Org. Electron. 2009, 10, 34

(17) Udum, T. A.; Durmus, A.; Gunbas, G. E.; Toppare, L. Orq. Electron. 2008, 9, 501

(18) Mortimer, R. J.; Graham, K. R.; Grenier, C. R. G.; Reynolds, J. R. ACS Appl. Mater. Interfaces 2009, DOI: 10.1021/am900431z.

(19) Zhang, C. F.; Liu, A.; Chen, M.; Nakamura, C.; Miyake, J.; Qian, D. I. ACS Appl. Mater. Interfaces 2009, 6, 1250.

(20) Jain, V.; Khiterer, M.; Montazami, R.; Yochum, H. M.; Shea, K. J.; Heflin, J. R. ACS Appl. Mater. Interfaces 2009, 1, 83.

(21) Street, G. B.; Clarke, T. C.; Kroumbi, M. T.; Kanazawa, K. K.; Lee, V. Y.; Pfluger, P.; Scott, J. C.; Weiser, G. Mol. Cryst. Liq. Cryst. 1982, 83, 253.

(22) Lux, F. Farbe Lack 1998, 104, 32

(23) Welsh, D. M.; Kloeppner, K. J.; Madrigal, L.; Pinto, M. R.; Schanze, K. S.; Abboud, K. A.; Powell, D.; Reynolds, J. R. Macromolecules 2002, 35, 6517 .

(24) Schwendeman, I.; Hwang, J.; Welsh, D. M.; Tanner, D. B.; Reynolds, J. R. Adv. Mater. 2001, 13, 634 
(25) Gaupp, C. L.; Welsh, D. M.; Reynolds, J. R. Macromol. Rapid Commun. 2002, 23, 885.

(26) Kumar, A.; Welsh, D. M.; Morvant, M. C.; Abboud, K.; Reynolds, J. R. Chem. Mater. 1998, 10, 896.

(27) Kumar, A.; Reynolds, J. R. Macromolecules 1996, 29, 7629.

(28) Corradini, A.; Marinangeli, A. M.; Mastragostino, M. Electrochim. Acta 1990, 35, 1757.

(29) Arbizzani, C.; Mastragostino, M.; Passerini, S.; Pileggi, R.; Scrosati, B. Electrochim. Acta 1991, 36, 837.

(30) Arbizzani, C.; Mastragostino, M.; Meneghello, L.; Morselli, M.; Zanelli, A. L. Appl. Electrochem. 1996, 46, 121.

(31) Huanga, S. W.; Ho, K. C. Sol. Enerqv Mater. Sol. Cells 2006, 90 , 491.

(32) Ribeiro, A. S.; Machado, D.; Faria dos Santos Filho, P.; De Paoli, M. A. Llectroanal. Chem. 2004, 567, 243.

(33) Garnier, F.; Tourillon, G. Electroanal. Chem. 1983, 148, 299.

(34) Bao, Z.; Dodabalapur, A.; Lovinger, A. L. Appl. Phvs. Lett. 1996, 69, 4108.

(35) Wang, G.; Swensen, J.; Moses, D.; Heeger, A. J. L. Appl. Phys. 2003, 93, 6137.

(36) Sirringhaus, H.; Brown, P. J.; Friend, R. H. Nature 1999, 401, 685.

(37) Sirringhaus, H.; Tessler, N.; Friend, R. H. Science 1998, 280, 1741.

(38) Chang, J. F.; Sun, B.; Breiby, D. W.; Nielsen, M. M.; Sölling, T. I.; Giles, M.; McCulloch, I.; Sirringhaus, H. Chem. Mater. 2004, 16, 4772

(39) Li, G.; Shrotriya, V.; Huang, J.; Yao, Y.; Moriarty, T.; Emery, K.; Yang, Y. Nat. Mater. 2005, 4, 864.

(40) Li, G.; Yao, Y.; Yang, H.; Shrotriya, V.; Yang, G.; Yang, Y. $\underline{A d v}$ Funct. Mater. 2007, 17, 1636.
(41) Chen, H. Y.; Yang, H.; Yang, G.; Sista, S.; Zadoyan, R.; Li, G.; Yang, Y. L.Phvs. Chem. C 2009, 113, 7946.

(42) Roncali, J.; Garreau, R.; Yassar, A.; Marque, P.; Garnier, F.; Lemaire, M. L.Phvs. Chem. 1987, 91, 6706.

(43) Campoy-Quiles, M.; Ferenczi, T.; Agostinelli, T.; Etchegoin, P. G.; Kim, Y.; Anthopoulos, T. D.; Stavrinou, P. N.; Bradley, D. D. C.; Nelson, J. Nat. Mater. 2008, 7, 158.

(44) Miller, S.; Fanchini, G.; Lin, Y. Y.; Li, C.; Chen, C. W.; Su, W. F.; Chhowalla, M. L. Mater. Chem. 2008, 18, 306.

(45) Zhao, Y.; Xie, Z.; Qu, Y.; Geng, Y.; Wang, L. Appl. Phvs. Lett. 2007, 90, 043504.

(46) Yang, H.; Shin, T. J.; Yang, L.; Cho, K.; Ryu, C. Y.; Bao, Z. Adv. Funct. Mater. 2005, 15, 617.

(47) Brinkmann, M.; Wittmann, J. C. Adv. Mater. 2006, 18, 860.

(48) Chang, Y. M.; Wang, L. L. Phvs. Chem. C 2008, 112, 17716.

(49) Sze, S. M. Physics of Semiconductor Devices, 2nd ed.; Wiley: New York, 1981.

(50) Sundfors, F.; Bobacka, J.; Ivaska, A.; Lewenstam, A. Electrochim. Acta 2002, 47, 2245.

(51) Ouyang, J.; Xu, Q.; Chu, C. W.; Yang, Y.; Li, G.; Shinar, J. Polvmer $2004,45,8443$.

(52) Huang, J. H.; Kekuda, D.; Chu, C. W.; Ho, K. C. L. Mater. Chem. 2009, 19, 3704.

(53) Fei, J.; Lim, K. G.; Palmore, G. T. R. Chem. Mater. 2008, 20, 3832.

(54) Bhandari, S.; Deepa, M.; Srivastava, A. K.; Lal, C.; Kant, R. Macromol. Rapid Commun. 2008, 29, 1959.

AM900573Q

2828

ACSAPPLIED MATERIALS
\&INTERFACES

VOL. $1 \cdot$ NO. $12 \cdot 2821-2828 \cdot 2009$

Huang et al.

www.acsami.org 